Article

\title{
HOW INSENSITIVE: PRINCIPLES, FACTS AND NORMATIVE GROUNDS IN COHEN'S CRITIQUE OF RAWLS'
}

\author{
DANIEL KOFMAN \\ Department of Philosophy, University of Ottawa. Ottawa, Canada. ${ }^{2}$
}

\begin{abstract}
Cohen's hostility to Rawls' justification of the Difference Principle by social facts spawned Cohen's general thesis that ultimate principles of justice and morality are fact-insensitive, but explain how any fact-sensitive principle is grounded in facts. However, when facts $F$ ground principle P, reformulating this relation (as in Cohen's analysis) as conditional "If $F$, then $P$ " is trivial and thus explanatorily impotent. Explanatory, hence justificatory, force derives either from subsumption under more general principles, or precisely exhibiting value in light of relevant (actual or hypothetical) facts. In examples where no subsumption occurs, actual facts trivially become hypothetical facts, an empty formalism. Indeed, Rawls' grounding of principles of justice in "conditions of life" can easily be reformulated as a conditional principle "sensitive" only to hypothetical such conditions, and thus formally fact-insensitive, for all Cohen's ire against Rawls's grounding.

Moreover, any plausible "ultimate fact-insensitive principle" must be intricately qualified, which tacit ceteris paribus clauses mask. Each qualification implies prioritisation of one principle over another in conceivable circumstances, and wherever the now qualified principle is given scope, that too implies prioritisation over competing principles in typical circumstances. Any principle is thus sensitive to conceivable circumstances of application, as recognised by more sophisticated intuitionisms. Nontrivial ultimate principles - luck egalitarianism, act utilitarianism, etc. - require defense, which inevitably involves showing how they best interpret and respond to facts about human needs, goals, and capacities in predictable circumstances. Finally, the
\end{abstract}

\footnotetext{
${ }^{1}$ This paper culminates a debate over many years, including at a weekend seminar that Jerry and I gave in 2003 at Kellog College, Oxford. I don't know if Jerry would have been persuaded by this, my final word, but I believe he would at least have appreciated my nod in the title to the great Brazilian songwriter Antonio Carlos Jobim. I wish to thank Hilliard Aronovitch and two anonymous referees for helpful comments on an earlier version of the paper.

${ }^{2}$ Daniel Kofman has taught philosophy for seven years at the University of Ottawa, and previously for eight years at University of Oxford. His seminar with Jerry Cohen on "The Grounds of Morality" is the origin of this paper. He has published articles and book chapters on justice, sovereignty, territoriality, self-determination, secession, and national rights.

Daniel Kofman enseigne la philosophie à l'Université d'Ottawa depuis sept ans, et a enseigné pendant huit ans à l'Université d'Oxford. Il a donné un séminaire avec Jerry Cohen sur "Les Fondements de l'Éthique " qui est à l'origine de cet article. Il a publié des articles et des chapitres de livres sur la justice, la souveraineté, la territorialité, l'auto-détermination, la sécession, et les droits nationaux.
} 
substantive debate between Rawls and Cohen about which facts are relevant to evaluating the DP is only obscured by the doctrine of fact-insensitivity.

\section{Resumé}

L'hostilité de Cohen envers Rawls fondant le principe de différence sur des faits sociaux a engendré sa théorie générale selon laquelle les principes ultimes de justice et de moralité ne sont pas sensibles aux faits, mais explique comment n'importe quel principe sensible aux faits est ancré dans les faits. Pourtant, quand les faits $F$ expliquent un principe $P$, une reformulation de cette relation (comme dans l'analyse de Cohen) dans la forme conditionnelle " si F, alors $P$ " est triviale et n'apporte rien en termes d'explication. La force explicative et justificative, vient soit de la subsomption par des principes plus généraux soit, lorsqu'il n'y a pas subsomption, précisément parce qu'elle apporte de la valeur à la lumière de faits réels ou hypothétiques. Dans les exemples où il n'y a pas de subsomption, des faits réels deviennent trivialement des faits hypothétiques, un formalisme vide. La manière dont Rawls fonde ses principes de justice sur des " conditions de vie " peut facilement être reformulée comme s'ils étaient des principes conditionnels "sensibles " uniquement à des conditions hypothétiques, devenant ainsi formellement insensible aux faits, esquivant la colère de Cohen contre la méthode fondatrice de Rawls.

En outre, n'importe quel "principe insensible aux faits " plausible doit être qualifié de façon détaillée, ce qui est masqué par les clauses tacites "toutes choses étant égales par ailleurs ». Chaque qualification implique la priorisation d'un principe sur un autre dans des circonstances concevables, et partout où le principe maintenant qualifié est censé être appliqué, cela implique aussi la priorisation sur des principes alternatifs dans des circonstances typiques. N'importe quel principe est ainsi sensible à ses domaines d'application concevables, comme les intuitionnismes sophistiqués le reconnaissent. Les principes ultimes non triviaux - l'égalitarisme des chances, l'utilitarisme des actions, et cetera - doivent être défendus, ce qui implique inévitablement que l'on montre comment ils interprètent et rendent compte de faits relatifs aux besoins, objectifs, et capacités humains dans des circonstances prévisibles. Par conséquent, le débat substantif entre Rawls et Cohen à propos des faits qui sont pertinents dans la formulation du principe de différence est obscurci par la doctrine de l'insensibilité aux faits.

\section{Key Words:}

Cohen; justice; difference principle; fact-sensitive principle; Rawls

\section{Mots-clés:}

Cohen; justice; principe de différence; principe sensible aux faits; Rawls

Jerry Cohen hoped his fact-insensitivity thesis would be his most enduring, as it was his most profound, contribution to philosophy. Indeed if the thesis were correct it might have proved his crowning legacy. In fact, it is elaborated with a sophistication that can ambush critics; many denounce it, but instead of precise objections recite methodological creeds that fail to engage with the characteristic rigour of Cohen's arguments. His deployment of the thesis to assail 
the Rawlsian doctrine has in particular not been adequately answered. Yet the theory is still wrong, or so I shall argue. ${ }^{3}$

I begin with remarks showing how the thesis originated in Cohen's critique of the difference principle (DP). Cohen does raise an interesting challenge especially for Rawlsians. The latter, but many others, consider morally inadequate a rejection of oppression merely on grounds of utilitarian "actuarial calculations" ${ }^{4}$ that such injustice supposedly would not maximise longterm aggregate happiness. Yet Rawls appears to rely on actuarial calculations of his own to defend the DP against worries that it would permit excessive inequalities. Cohen's retort is that in both cases the problem is that the claims of justice itself are being sidelined (Cohen 2008, e.g. 259).

Cohen then repudiates Rawls' view that a theory of justice must be justified (in part) by social and psychological facts. For Cohen ultimate principles of justice and morality are not factsensitive at all (facts are not among their grounds). Recognition that these (timeless and universal) fact-insensitive principles occupy the summit of moral reasoning explains the wrongness of both Rawls' inclusion of the DP within justice, and his constructivist method of identifying principles of justice.

After brief exposition of Cohen's doctrine, I turn to criticism of it. I argue that Rawls' principles and professed fact-dependence can be reformulated (if one is so pedantically inclined) to be "sensitive" only to hypothetical facts consistent with Cohen's doctrine of actual-factinsensitivity. ${ }^{5}$ In other words, the metaethical debate is largely a pseudo-issue, a philosophical tempest in a teacup.

Secondly, alleged grounding by ultimate fact-insensitive principles is deceptive: tacit ceteris paribus qualification of any plausible such principles masks incomplete grounding, and the implied prioritisations constitute responses to conceivable circumstances. More sophisticated intuitionisms than Cohen's recognise this. Moreover, controversial doctrine-principles proferred as non-trivial ultimate principles - luck egalitarianism, act utilitarianism, etc. ${ }^{6}$ - require defense,

\footnotetext{
${ }^{3}$ Arguably it shares with its constructivist opponent a penchant for formalism that lends normative philosophy, or the substantive views espoused, a halo of esoteric power beyond its actual capacity to gain rational consensus. I don't pursue that idea here. The Rawlsian Pogge accuses Cohen of "friendly bullying" (Pogge 2009), presumably in favour of his substantive egalitarian view. Constructivists might be similarly charged. I believe Cohen's primary motive was in fact to contribute lastingly to grand metatheory.

${ }^{4}$ Rawls 1971, 1999, 137. All citations herein are from this second edition.

${ }^{5}$ Kurtulmus agrees that Rawls' claims can be rendered consistent with Cohen's, but for reasons I do not find compelling; see note 19 below (Kurtulmus 2009). Pogge's paper (2009) came into my hands after I had written mine, and makes some similar arguments, including the possibility of reformulating fact-sensitive principles to be fact-insensitive. He puts this in terms of building context-dependence into the principle ("internalising" it). I agree, but express the point in terms of sensitivity to hypothetical instead of actual facts, because, as explained in section 3.1, Cohen attempts to exploit the point that the universalisable prescriptive element of a moral claim makes no existential commitments. It is in that sense fact-free. Context-dependence is also relevant to the discussion of qualification in section 3.2. See Pogge 2009, 88-109.

${ }^{6}$ Cohen, correspondence with author, October 27, 2007.
} 
which inevitably involves showing how they best interpret and respond to facts about human needs, goals, and capacities in predictable circumstances. Finally, I argue that the substantive debate between Rawls and Cohen about which facts are relevant to the DP is only obscured by the doctrine of fact-insensitivity.

\section{Introduction}

Cohen's theory of fact-insensitive principles developed from his attack on Rawls' difference principle (DP), which many egalitarians have worried opened the door to significant inequality, provided the advantaged could hold for ransom the services that would improve the position of the worst off (the condition supposedly agreed by Original Position (OP) parties for permitting inequality). This "left" critique of Rawls' DP, essentially the topic of Cohen's entire Rescuing book, can take several forms. ${ }^{7}$ Depending on how the characterization of economic, social, and psychological "reality" unravels, a standard egalitarian apprehension is that the DP could turn Rawls-the-would-be-egalitarian into a von Hayek or Milton Friedman in egalitarian clothing. ${ }^{8}$ (Don't they say everyone is better off under free market capitalism? Doesn't virtually everyone claim a free market makes a larger pie to go around? And isn't freedom itself the supreme primary good on Rawls' own theory, which von Hayek, Friedman, and supporters have held is best secured by a free market?)

Rawls replies that excessive inequalities will not ensue from adoption of the DP because it is simply not the case - in part given the psychological and socioeconomic facts ${ }^{9}$ - that great inequalities would be necessary to benefit the worst off. Moreover, certainly far less inequality can be justified by the DP than currently occurs. Cohen's rejoinder is that whether facts are as Rawls claims, they are irrelevant to justice. Rawls' defense thus recalls how conciliatory utilitarians parry justice-based objections by pleading that equal distribution supposedly fosters utility by envy reduction and a putative declining marginal utility of increased wealth. Besides doubting that greater equality maximises aggregate welfare, one may object that anyway this is beside the point: equality (or priority of the poorest) should count morally in itself.

\footnotetext{
${ }^{7}$ Not the entire battery of arguments against it in Cohen 2008 takes a form outlined below, but many do.

${ }^{8}$ In post-Parfitian terms Rawls was never strictly an egalitarian, but either a prioritarian or multi-principle theorist, where one of the principles is prioritarianism: giving priority to raising the level of the worst off, but never levelling down for the sake of greater equality if no one benefits absolutely. (More accurately, Rawls seems to have been a luck prioritarian, in which case Cohen's charge that Rawls is inconsistent in endorsing both equality and Pareto-optimal departures from it would be inaccurate. I cannot pursue substantive questions about justice or Rawls' view of same here.) Nevertheless, in looser terms Rawls has inspired the broader philosophical movement of modern egalitarianism.

${ }^{9}$ More precisely, Rawls argues that the application of the other principles of justice - equal liberty and equal opportunity - coupled with basic economic and psychological facts will ensure a competitive supply of (what I suppose would be) skilled labourers, professionals, and entrepreneurs sufficient to hold down the price of such talent. I am interpreting his remarks on 136-7.
} 
In other words justice itself independently of general utility favours equality, which even conciliatory utilitarians ignore. Similarly ${ }^{10}$ one may question whether an institutionalised DP will bridle inequality, but also regard the ransom demanded by the talented as selfish, thus no part of "justice itself" (though acceptable within "regulative rules" - practical guidelines adopted in face of "feasibility constraints"). Incentives for the selfish may well be justified all things considered, but all things considered are by definition not only justice considered, and not all that is justified is necessarily just. ${ }^{11}$

Concern for "justice itself" may be derided as "Platonist", but Cohen - embracing the description $^{12}$ - seems to have identified an interesting double standard in attitudes to utilitarian and Rawlsian contractualist appeal to facts. Rawls' complaint that utilitarianism fails to "take seriously" the "separateness of persons" is widely accepted. But this insistence that distribution not just aggregation and "actuarial calculations" matters, ${ }^{13}$ could ring hollow if that very distribution becomes hostage to the actuarial calculation of how much beyond equality entrepreneurs and professionals will need to be paid off for services rendered. For what does necessity amount to here? Within Rawlsian constructivism it cannot be a moral but only a causal concept: whatever is empirically required to induce the talented to offer their services that will benefit the worst off. Rawls is quite explicit: while OP parties should not trust actuarial calculations to protect liberty, but should embed the "moral ideal" of protecting liberty directly into principles of justice, the DP "presupposes ... a certain theory of social institutions" that will ensure that "in a competitive economy ... with an open class system excessive inequalities will not be the rule". ${ }^{14}$

\footnotetext{
${ }^{10}$ Cohen provides a version of this analogy to the contrasting ways one can criticise utilitarianism, Cohen 2008, Ch. 6, section 19, 263-268.

${ }^{11}$ This point occurs throughout Cohen 2008, Chapter 7, e.g. 283, 291, 305.

${ }^{12}$ Cohen praises Plato for seeking ideal moral principles, including justice, beyond mere situational judgements, Cohen 2008, 91. Less explicit is the whiff of positivist fact-value dichotomy pervading Cohen's later work. He denies his thesis is affected by that controversy, but examines only one version of deriving "ought" from "is" statements: deductive inferences from the meaning of terms used in factual statements. (E.g. 'George is in pain' implies by virtue of the meaning of the terms that 'George ought to be assisted').

${ }^{13}$ Rawls: "It is often objected, for example, that utilitarianism may allow for slavery and serfdom, and for other infractions of liberty. Whether these institutions are justified is made to depend upon whether actuarial calculations show that they yield a higher balance of happiness. To this the utilitarian replies that the nature of society is such that these calculations are normally against such denials of liberty." Rawls 1971, 1999, 137.

${ }^{14}$ Rawls 1971, 1999, 137. Rawls offers two reasons why the OP parties shouldn't rely on "actuarial calculations" of utilitarianism: (1) the calculations may be wrong; (2) even if they are correct, "there is a real advantage in persons' announcing to one another once and for all that even though theoretical computations of utility always happen to favour the equal libertes (assuming that this is indeed the case here), they do not wish that things had been different." The conception of justice is public, and there are "benefits of this collective profession" for stability, 139. Rawls never quite explains why similar benefits would not follow a public "announcement" that "once and for all" everyone ought to work according to their ability without demanding or expecting more than equal pay. Nor is the "benefit" of not making liberty hostage to aggregate-maximising calculations merely about stability: if liberty is morally valuable then it ought to be valued in a just society (stability being a by-product of this recognition).
} 
This issue motivates Cohen's hostility to the idea that ultimate normative principles are fact-sensitive. As Cohen observes, the quoted passage surreptitiously relies on an inexplicit background principle that "excessive inequalities" are wrong. From "a theory of social institutions" (a species of actuarial calculation) OP parties derive the factual claim that inequalities will fall within a certain range, which is then deemed acceptable. But only if inequality were considered wrong, or equality morally valuable, would there be a moral standard of "excess" requiring demonstration that the social facts prevent excessive inequality. (Compare the utilitarian motivation for demonstrating that proper consequentialist reckoning will not endorse slavery). Otherwise no inequality necessary to benefit the worst off would be excessive. Thus the normative principle prescribing equality is logically prior to judging which inequality is excessive, and Cohen then claims that this principle is actually independent of any facts.

Now that latter claim certainly does not follow from the normative principle's being independent of the particular institutional facts to which Rawls alludes. That people ought to be treated as equals may itself be grounded in any number of facts about humans, and therefore be fact-sensitive. Cohen's standard line against such challenges ${ }^{15}$ is that any such further facts could be grounds of the principle only if there were an even higher, ultimate principle that is not factsensitive at all: if there are beings of such a nature (capable of rational life-plans, self-conscious, and whatever else one thinks relevant) then they ought to treat each other as equals. That principle, if true, holds whether such beings even exist, thus irrespective of any facts (other than normative facts, if there are such). Rawls' DP - that given the fact that some won't work without greater than equal pay, one ought to provide them it iff that benefits the worst off - is factsensitive (as is the judgement that the resultant inequalities will be moderate) thus not at the abstract summit of justice, where reside only fact-insensitive principles.

\section{Cohen's doctrine of normative structure}

Cohen defines a fact-sensitive principle as "reflecting" or grounded by a fact. A "fact" is any true proposition other than a moral one (if there are such). But any fact-sensitive principle is always ultimately grounded also by another principle not sensitive to facts: "Principles that reflect facts must, in order to reflect facts, reflect principles that don't reflect facts" (Cohen 2008, 232).

For example, if principle $\mathrm{P}$ (keep one's promises) is affirmed because of fact $\mathrm{F}$ (promisekeeping enables promisees to pursue their projects) $\mathrm{F}$ alone does not justify $\mathrm{P}$. F is a ground of $\mathrm{P}$ only because of some "more ultimate" principle P1: Everything equal, we should help people pursue their projects. Now this principle would be affirmed independently of F; its affirmation, Cohen says, would survive denial of F. Possibly one would affirm P1 only in light of facts other than F. Then P1 is not ultimate. Suppose one affirms P1 because one believes F1: helping people

Similarly, if equality is morally valuable then it should be publicly valued, and departures disvalued even if necessary evils. Rawls, however, eschews such "perfectionist" moralism.

${ }^{15}$ I extrapolate here from his remarks about promise-keeping (see next section) and other examples. 
pursue their projects shows respect for rational beings capable of framing and pursuing life plans. Then F1 in turn could ground P1 only if some P2 prescribed respecting rational beings (including by helping them pursue their projects). P2 would then be an ultimate fact-insensitive principle: it is not sensitive to any facts, and its affirmation would survive denial of F1. Cohen holds that no case of a fact grounding a principle would require exceeding a few steps ("say five") before reaching the ultimate fact-insensitive principle in light of which the lower principles are grounded by facts. ${ }^{16}$

Mundane judgements, provided they are normative - enjoining some act - are similarly analysable: "Turn off the lights when vacating the room" is a fact-sensitive P grounded in F ("Lighting vacant rooms wastes electricity", and perhaps facts about harm caused by wasting electricity). But F could not ground P without P1: "Waste is wrong". ${ }^{17}$ Again, the "affirmation of $\mathrm{P} 1$, as opposed to whether or not the affirmation induces her to affirm P itself, has nothing to do, essentially, with whether or not she believes that F" (Cohen 2008, 234). P can be sensitive to F only because of P1, which is insensitive to F. Moreover, either P1 is not sensitive to any facts, or is only because of some $\mathrm{P} 2$ (or P3, etc.) which is not; the latter is thus the ultimate fact-insensitive principle grounding the original P. Here P1 is fact-insensitive since one who affirmed it would do so even if nobody wasted or nothing was wasteful in the actual world. In a possible world where waste occurred, waste would be wrong.

Cohen insists that the thesis is logical not epistemic. That is, the ultimate fact-insensitive principle is what the person affirming $\mathrm{P}$ is committed to; the person need not know P1 to know P. Cohen compares this to knowledge of a causal relation. I can know that flicking the switch turns the light on without knowing anything about electricity or even that electricity is involved. ${ }^{18}$ And I might know that $\mathrm{P}$ - hurting my acquaintances is wrong - without knowing why. Discovering the fact-insensitive principle P1 that harming innocents is wrong would explain $\mathrm{P}$ even if I knew $\mathrm{P}$ without it.

Fundamental moral principles, including justice, exhibit insensitivity to not only facts but values and principles distinct from them. Thus, "whatever their content may be, fundamental principles of justice are in no way dependent on the character of any facts, or, indeed, and equally importantly for my purposes, on any considerations of value or principle that are not considerations of justice" (Cohen 2008, 281). This exposes a further failing of Rawlsian constructivism. Not only do OP parties choose principles in light of general socio- economic facts, thus violating the fact-insensitivity thesis of principles of justice, but they choose them as optimal principles to live by, which necessarily means by weighing values and principles other than justice. "[S]imply because they are the all-things-considered best principles to live by, optimal all-things-considered principles are therefore not necessarily the best principles considered from the point of view of justice alone" (Cohen 2008, 275).

\footnotetext{
${ }^{16}$ Cohen 2008, Ch. 6, sects. 5-6, 233-236. I have slightly abridged and altered Cohen's example.

${ }^{17}$ Cohen, lecture at All Souls College, circa 2003.

${ }^{18}$ Correspondence with author, October 2007.
} 
To recall, it is essential to Rawls' OP parties that they choose principles that are stable (generating their own support), predicted in light of general facts to benefit the worst off, and can be publicly endorsed, including in light of predicted effects of doing so. But this, thinks Cohen, proves that the constructive procedure misidentifies the resultant regulative rules (as Cohen calls them) accommodating these values with justice. Not that one shouldn't live by optimal regulative rules, if the procedure really could find them, but political philosophers should want to know what justice itself requires, both for the sake of philosophical clarity, but also because such knowledge would clarify the degree of compromise with actual justice, whether it is necessary and for how long, and whether inculcating untainted principles of justice might eventually render the compromises unnecessary.

Cohen cites several passages from Rawls defending the reliance of the OP parties on general facts about human nature. One encapsulates what exercises him about Rawls' method: "Conceptions of justice must be justified by the conditions of our life as we know it or not at all." (Rawls, 1971, 1999, 398; Cohen 2008, 229). Another, previously cited, relates directly to the DP:

Contract theory agrees, then, with utilitarianism in holding that the fundamental principles of justice quite properly depend upon the natural facts about men in society. This dependence is made explicit by the description of the original position: the decision of the parties is taken in the light of general knowledge. Moreover, the various elements of the original position presuppose many things about the circumstances of human life. Some philosophers have thought that ethical first principles should be independent of all contingent assumptions, that they should take for granted no truths except those of logic and others that follow from these by an analysis of concepts. Moral conceptions should hold for all possible worlds. Now this view makes moral philosophy the study of the ethics of creation: an examination of the reflections an omnipotent deity might entertain in determining which is the best of all possible worlds. Even the general facts of nature are to be chosen. Certainly we have a natural religious interest in the ethics of creation. But it would appear to outrun human comprehension. From the point of view of contract theory it amounts to supposing that the persons in the original position know nothing at all about themselves or their world. How, then, can they possibly make a decision? A problem of choice is well defined only if the alternatives are suitably restricted by natural laws and other constraints, and those deciding already have certain inclinations to choose among them. Without a definite structure of this kind the question posed is indeterminate. For this reason we need have no hesitation in making the choice of the principles of justice presuppose a certain theory of social institutions. Indeed, one cannot avoid assumptions about general facts any more than one can do without a conception of the good on the basis of which the parties rank alternatives.... It is evident... 
that both general facts as well as moral conditions are needed even in the argument for the first principles of justice (Rawls 1971, 1999, 137-8). ${ }^{19}$

Rawls notes that theories differ as to the relative roles they assign to general facts and moral ideals. Utilitarianism (presumably Millian) depends on sociopsychological facts (as appraised by "actuarial calculations") to prevent unacceptable degrees of inequality; justice as fairness embeds this ideal "more directly" into its principles. But it also qualifies this ideal with the DP on grounds that here the facts will, as in Millian utilitarianism, prevent "excessive inequality" from arising. Cohen sees a muddle here. "Excessive" presupposes a principle of equality, yet the OP parties, seeking optimal regulative rules are blind to this moral ideal. The constructivist method confuses the fact-insensitive ideal of justice with the concoction of facts and principles that the OP parties balance in their quest for optimal regulative rules.

\section{Objections to the fact-insensitivity thesis}

3.1. I do not assess here Rawls' constructivism nor his reasoning for the DP, for neither of which I hold any brief. Nor do I endorse herein any substantive position about justice, whether egalitarian, prioritarian, or anything else. My sole concern is to assess Cohen's metaethical doctrine and its use in criticising Rawls. I shall defend the startling assertion that the Rawlsian OP parties' reliance on facts about human psychology and society, and Rawls' claim that a conception of justice must be justified by the conditions of life, can be rendered strictly speaking consistent with views Cohen tacitly accepts, despite his doctrinal pronouncements. Rawls declares that the parties are not choosing principles of justice for all possible worlds, but only for their world (in his later work further restricted to their society). All Rawls means here is that facts about the capacities as well as needs and purposes of the subjects of justice must be taken into account in determining which principles of justice apply to them. Principles that apply to humans may not apply to frogs or angels, and principles that apply to humans in conditions of moderate

\footnotetext{
19 The phrase "But it would appear to outrun human comprehension" might appear to support Kurtulmus' contention that Rawls thinks theories are supported by facts just in the sense that we cannot trust our intuitions about cases not arising in this world (Kurtulmus 2009, 490). My objection to this interpretation is threefold: 1.The rest of the passage, and others (e.g. 136-138, 397-398), show that this is not Rawls' primary reason for thinking facts ground principles. He thinks facts about human nature and society render determinate (see quoted passage) questions about what one ought to do, or how goods ought to be distributed, that would be entirely indeterminate if all factual possibilities were open. Nor have I found any other passage supporting Kurtulmus' interpretation. 2. The claim is patently false. We have countless intuitions about cases not of our world of which we are as certain as of any in ours. And that is (partly) because 3. Moral judgements about this world counterfactually imply judgements about other worlds. If hate speech is offensive because people are sensitive to it, in a similar world but where people were indifferent to hate speech, it would not be offensive. Pogge's "pragmatist" rejection of our attempt "to extend our moral reasoning to all possible worlds and contexts" misses this point (Pogge 2009, 109).
} 
scarcity may not apply to humans outside these conditions. ${ }^{20}$ And to anticipate my later argument, principles that apply to people from whom it is reasonable to demand degree of sacrifice $\mathrm{x}$ for the sake of the general welfare do not apply to those from whom sacrifice $\mathrm{x}$ would be unreasonably overdemanding. ${ }^{21}$

There are principles which apply to a modern industrial state but not face-to-face hunting-gathering societies or families. This is obvious with corrective justice. Acquaintance societies have capacities of remonstration and rehabilitation, and levels of risk from miscreant behaviour, different from those of large societies of strangers, and the same act of punishment can have very different effects depending on in which type of grouping it is performed. Reasonable demandingness - what is appropriate to demand of moral agents - with respect to both distribution and other duties, surely varies as well from large societies of strangers to faceto-face phratries and to families.

I presume that Cohen would not have objected to any of the above. His line of defense would have to be that principles qualified by the circumstances to which they apply depend for their justification on higher principles that are true, or would be affirmed by someone with clarity of mind, independently of whether such circumstances hold. These would typically take the form: If circumstances $\mathrm{C}$ (or facts $\mathrm{F}$ ) hold, then one ought to do $\mathrm{x}$. Pogge calls this "internalising" the context of application into the principle itself; for reasons that will become clear below, I prefer to speak of reformulating the principle as applying to hypothetical (as opposed to actual) facts. So if Rawls says that principles of justice must be justified by conditions of life as we know it, and Cohen objects that conditions of life could justify a principle only because of a more ultimate principle that was insensitive to such conditions, Rawls could (with a shrug toward pedantry) reformulate the said principles to render them hypothetical: If conditions of life are as such, goods ought to be distributed in such a way (encapsulated by the two principles of justice). Affirmation of this principle, Cohen would have to agree, survives denial that the specified conditions actually obtain.

This brings me to a central problem with Cohen's notion of fact-insensitivity: it runs together at least four quite distinct features:

\footnotetext{
${ }^{20}$ For similar points, see Pogge 2009, esp. 96, including notes 7 and 8. Cohen argues at length that circumstances of justice do not affect the content of principles of justice but only the possibility of their application, Cohen 2008, 331336. But as I argue below (in agreement with Pogge), this distinction is the source of most of the confusion surrounding Cohen's thesis.

${ }^{21}$ Cohen himself holds that we have "the right to be something other than an engine for the welfare of other people: we are not nothing but slaves to social justice". Thus the state must not "legislate so invasively and comprehensively that the individual lacks scope for the exercise of what belongs within his own prerogative", Cohen 2008, 10. Clearly Cohen is here determining the appropriate degree of self-sacrifice it is reasonable to demand, given - I presume, though he is not explicit - facts about human needs and capacities. If some humans were natural slaves incapable of deliberating about or framing a conception of their own good, such a prerogative for them would lack justification. The dispute of moderns including Cohen with Aristotle on this important issue is over facts.
} 
(1) The fact-insensitive principle is something one is logically committed to by affirmation of the corresponding fact-sensitive principle, whether or not it is thought.

(2) The fact-insensitive principle can be rationally affirmed independently, or consistent with the denial, of the relevant facts.

(3) The fact-insensitive principle explains the grounding of the fact-sensitive principle by the facts.

(4) Ultimate fact-insensitive principles do not require grounding (at least beyond showing that they promote recognised value) - they are rock bottom, or ultimate top, depending on one's metaphorical preference, in the justificatory process.

I shall postpone discussion of the fourth feature until next section. To begin with the first feature, affirming a proposition $\mathrm{P}$ commits one to an infinite number of other propositions trivially implied by $\mathrm{P}$ : "P and $\mathrm{P}$ ", "P or P", etc. When $\mathrm{P}$ is a fact-sensitive principle grounded in fact $F$, the utterer's commitment to another proposition P1 "If $F$, then $\mathrm{P}$ " may be entirely trivial. In a particular judgement where $\mathrm{F}$ conjoins several relevant facts, and $\mathrm{P}$ is a judgement rendered in light of those facts, it is hardly enlightening to observe that the utterer is committed to a further proposition "If $\mathrm{F}$ then $\mathrm{P}$ " ${ }^{22}$ I return to this in the next section discussing ceteris paribus clauses.

The second feature, again, seems uninteresting if the principle one is committed to is a trivial conditional derived from an affirmation of $\mathrm{P}$ in light of F. Of course the entailed "If $\mathrm{F}$ then $\mathrm{P}$ " would be affirmed independently of F obtaining. But this leads to the main problem, the third feature. That the fact-insensitive principle explains the grounding by the facts of the fact-sensitive principle does not follow from the other two formal features; it is an independent requirement (although Cohen sometimes speaks as if these features were equivalent or mutually implicit). This added feature is crucial both to avoid the triviality of the first two features and ultimately to press the claim that justice is a fact-insensitive principle with irreplaceable explanatory power the point of the entire doctrine. This explanatory property indeed makes sense when explaining the grounding of a narrow moral judgement by a more general one. ${ }^{23}$ Thus, in moving from "Keep one's promises" to "Help people pursue their projects", the subsumption of the promisekeeping duty under a more general principle lends explanatory power (analogous to the covering law theory of scientific explanation); similarly if there were a further generalisation to "people's happiness should be promoted" or "beings capable of framing and realising life-plans should be accorded respect". Or, ascending from "Unused lights should be extinguished" to "Waste is

\footnotetext{
${ }^{22}$ Cohen denies his doctrine resembles "What the Tortoise Said to Achilles" (Lewis Carroll) because he is not adding a rule of inference as premise, nor engendering an infinite regress (the stopping point arrives in a few steps). But those differences aside, Cohen and the tortoise share insistence on adding a premise that is uninformative because already implicit in the given inferential relation. It can be a final step but still trivial (Cohen 2008, 238-9). Cohen thinks the added premise is not trivial because it is required to justify the previous inference. So did the tortoise; more on this below.

${ }^{23}$ On this, see Pogge 2009, 97.
} 
wrong" (or whatever the relevant higher fact-insensitive principle) carries explanatory force because the "higher" principles are more general.

Compare a principle P said to apply because of some fact F. Suppose "in support" of this grounding one can adduce only that another principle P1 holds: "If F then P". P1 will bear the first two features cited above: the affirmer of $\mathrm{P}$ because of $\mathrm{F}$ will be committed to it, and would affirm it even if $\mathrm{F}$ were denied. But the third feature is entirely lacking. Since the utterer had already stated that $\mathrm{P}$ is grounded by $\mathrm{F}$, her commitment to P1 contributes no new knowledge, hence no explanatory power. Cohen thus mixes, in illustrating his thesis, two distinct kinds of examples - where explanatory force is carried by greater generality (of the new principle), and where there is no explanatory force because no greater generality - thereby creating the illusion that the general thesis of ultimate fact-insensitive grounding is sound. This illusion is reinforced by his use of the thesis to attack the putative grounding of the DP by factual calculations that inequalities won't be excessive, where one might question whether that fact really grounds that principle.

Cohen's doctrine also exploits a general feature of moral reasoning. Philosophers from Kant to Hare and Mackie have highlighted the universalisability of the prescriptive aspect of any normative judgement. ${ }^{24}$ Even particular moral judgement J - "George ought to visit his mother in the hospital" - implies that anyone in a relevantly similar situation should visit his mother in the hospital; otherwise the "ought" would have no force. The prescriptive feature can be formulated as a "universal law": "Any being B in circumstance C ought to do act A", where C includes relevant non-relational (being a person, rational, etc.) or relational (being a son) properties of $\mathrm{B}$. Since "All Fs are G" is equivalent to "For all $\mathrm{x}$, if $\mathrm{x}$ is $\mathrm{F}$ then $\mathrm{x}$ is $\mathrm{G}$ ", universal laws can also be expressed as "If $\mathrm{B}$ is in circumstance $\mathrm{C}, \mathrm{B}$ ought to do A". ${ }^{25}$

Particular judgement $\mathrm{J}$ can thus be analysed into a prescriptive statement (in conditional or universal form), conjoined with an existential statement "There is something named George and its mother is in the hospital". The prescriptive statement, if true, would obtain even were the existential statement false, and could be rationally affirmed consistently with denial of the existential statement. However, this feature of prescriptive statements does not ensure that explanatory force is supplied by abstracting the prescription from the particular judgement. "If something is identical to George and is in the same situation as George, then it should visit its mother" contributes nothing to justifying J. By contrast, a universal prescription specifying the

\footnotetext{
${ }^{24}$ Kant, Groundwork 1785, 1798 and Critique 1788, 1993, Richard Hare 1977, John L. Mackie 1977.

${ }^{25}$ Like many readers of Cohen, Miller senses that the explanatory feature will be lost if the fact-insensitive principle trivially restates as a conditional the inferential relation between F and P. But he fails to formulate the objection coherently when he complains that "Cohen's thesis that fact-sensitive principles must reflect fact-insensitive principles becomes trivial if we include among the fact-insensitive principles conditional principles of the form if $\mathrm{F}$, then P'. For the thesis not to be trivial, the ultimate fact-insensitive principles that ground fact-sensitive principles must be unconditional in form" (Miller 2008, 35). But the problem is not the logical form. "Help the needy" and "If someone is needy you should help them" are logically equivalent. Miller's complaint is thus akin to objecting that Cohen fails to distinguish between "p or q" and "q or p".
} 
relevant features of George's special relation to his mother, her predicament, and his capacity in light of their relationship to help her, would explain and thus justify (the only relevant explanation here) the moral judgement. The resultant "principle" would be true, if true, even if no one occupied George's position, no mothers were hospitalised, and indeed were there no mothers or hospitals. Nevertheless the prescription is acutely sensitive to the hypothetical facts that members of special relationships can profoundly affect each others' well-being. This grounding of prescription in hypothetical facts can be generalised only so far, beyond which one reaches non-explanatory platitude and omits precisely the moral significance of the hypothetical facts.

This generates a fatal dilemma for Cohen's thesis. So-called fact-insensitive principles have explanatory force if they exhibit sensitivity to relevant hypothetical facts, but to contribute more enlightenment than was already available in the acknowledged grounding of the factsensitive principle in actual facts, they must do more than reformulate actual facts as hypothetical facts. Once one ascends to the most general level of description of the actual facts relevant for grounding the most general relevant principle, the move to a "higher" fact-insensitive principle is impaled on one of the two aforementioned horns, and becomes a trivial reformulation with no further explanatory contribution. ${ }^{26}$

3.2. Another problem is that Cohen ignores ceteris paribus clauses as if doing so were merely tedium-saving. However, the more complex the set of hypothetical facts in light of which a type of action is prescribed, the more obvious the triviality, or lack of explanatory force, in moving from the principle that is sensitive to properly qualified actual facts to one sensitive to similarly qualified hypothetical facts. "Keep one's promises" or "Do not waste" are immense simplifications. Promises, for instance, should not be kept if that would cause certain kinds and degrees of harm, although not any harm. Promises made under duress, coercion, without presence of mind, when deceived or lacking relevant information, lose some or all obligatory force. Trivial promises can be overridden by duties of beneficence. "Higher" principles - "Help people realise their projects", "Contribute to human happiness" - require qualification no less than lower ones. Thus fully articulated fact-sensitive principles will be sensitive to long conjunctions of factual conditions: $F_{1}$ and $F_{2}$ and... $F_{n}$. The corresponding fact-insensitive principle will need to repeat as hypothetical facts the same long list in the antecedent: "If $F_{1}$ and $\mathrm{F}_{2}$ and... $\mathrm{F}_{\mathrm{n}}$, then....". The failure of such a "fact-insensitive" principle to explain the grounding relation of the original principle in the original list of facts is glaringly obvious; nothing explanatory whatsoever is contributed by the alleged fact-insensitive principle.

Moreover, this reveals a much deeper problem. Qualification implies prioritisation. Harm avoidance or beneficence can override promise-keeping duties because of competition between values. To be sure Cohen is mindful of such conflict, warning against mistaking trade-offs with

\footnotetext{
${ }^{26}$ I.e. either it restates the actual facts as hypothetical or it moves to a "higher" platitude that omits reference to the relevant facts, hypothetical or not. Either move is trivial.
} 
stability, Pareto improvement, or publicity, however justified all-things-considered, for justice itself. It might therefore seem unfair to accuse him of underestimating the moral significance of qualification and prioritisation. Yet he appears to accept a false dichotomy between prioritisation which must occur in light of factual circumstances ("conditions of life as we know them"), and simply individuated principles at the "summit" of reasoning. Principles are injunctions to the promotion of some value, and any plausibly individuated principle tacitly implies a judgement that over a certain range of cases the selected principle ought to take priority; it would be otherwise pointless to elevate - and thus generalise - a particular judgement to the status of principle. All such implied prioritisations are circumstance-sensitive: they imply judgements about the relative weights of the value of the selected principle viz.-a-viz. competing values in conceivable circumstances. Since realisable value varies according to circumstance, relative weights of realisable competing value vary as well. The principle to keep promises implies judgement about the supersession of this duty under certain circumstances over doing what one feels like.

A close reading of Cohen's professions of intuitionism may lend support to the conjecture that he subscribed to a vision of competing a priori individuated principles as simplistic as the constructivist unitary prioritisation propounded by Rawls. Cohen accepts the intuitionist view of ethical reasoning as structured by a plurality of irreducible highest-order principles (Cohen 2008, 4-6). But the attitude in Prichard (1912) and Ross (1930) (and indeed Aristotle, Clarke and Reid) that complex reality is preferable to an illusory simplicity or neatness is accompanied by a sense of resignation:

[Principles] cannot all be satisfied all the time, nor do we have a method for systematically combining them. Discursively indefensible trade-offs are our fate. I do not say that such an intellectual predicament is satisfactory. But I do say that it is the predicament we are in (Cohen 2008, 4).

Or again,

I'm not saying that it's quite $\mathrm{OK}$ that things are vague, and it is undoubtedly more consequential in the moral than in the personal domain that they are. Like everybody else, I would prefer something better. But unlike some others, I don't think it's to be had (Cohen 2008, 6).

For classical and contemporary intuitionists, the complex reality of variance of realised value in varying circumstance (and hence the variability of relative weights of realised competing values in varying circumstances) is not a "predicament" to be lamented (unless one hankers after a cult-like simplicity), nor does it imply more "vagueness" than do oversimplified principles such as "Keep promises". Moreover, trade-offs are often "discursively indefensible" only in the sense that foundational beliefs (Modus Ponens, one plus one equal two) including in highest-order 
principles might be. The permissibility of deceiving a murderer to save life rests on the judgement that saving life trumps sincerity in virtually any circumstances, but there is nothing "vague" about this judgement, and if anything is discursively indefensible here, it might be the supreme value of human life (or whatever one takes as the relevant foundational belief, if one is foundationalist). But then any singly individuated principle resting on this belief (don't murder innocents) is no less "discursively indefensible".

The term "intuitionism" to describe unranked principle pluralism is therefore misleading: "intuition" is used by philosophers to range from the vaguest hunches to the most fundamental logical, mathematical, and ethical beliefs. An intuition with respect to a trade-off may be as firm as any intuition regarding an individuated principle, and if previous considerations were sound, adequately qualified non-platitudinous principles will already build in implied trade-offs as qualifications. Such prioritisations are obviously defensible, when so, in light of facts about what values are realisable under the relevant circumstances. Those prioritisations can often be generalised up to a point. So on one hand moral principles when non-platitudinous are shorthand expressions that more properly have complex qualifications; on the other hand prioritisations can often be elevated to some level of "principle" (such as the "clear and present danger" standard for overriding free speech). There is a degree of pragmatic and cultural nominalism - which is not to say entire arbitrariness or subjectivity - in how we carve up and abstract from the myriad judgements we make to yield a set of higher principles.

The prioritisation of principles is a major concern of the work of Rawls. I have no wish to defend Rawls' unitary prioritisation of his two principles, nor his constructivist method of deriving it. However, Cohen nowhere objects to the unitariness of the prioritisation per se (which exercises intuitionists such as Urmson or Feinberg); his anti-constructivism focuses on the consideration by the OP parties of facts, and of values other than justice. To recall, Cohen concludes that the resultant principles, precisely because they are all-things-considered optimal principles to live by, are regulative rules. But if rankings of principles in given circumstances are justified, compliance with regulative rules based on those rankings are as obligatory as abiding by any singly individuated principle. Insofar as the objection is that the rankings are sensitive to factual circumstances, we can again reformulate them as sensitive only to hypothetical circumstances. And since they are obligatory, there must be an ultimate "fact-insensitive" principle, "Comply with the right regulative rules for your society". This ultimate principle combines with the "fact-insensitive" principle that if facts are such as obtain in modern industrial societies, the optimal regulative rules are the two principles prioritised as in the OP. Thus at least as far as Cohen's fact-sensitivity objection is concerned (his mixing values objection will be briefly treated below), Rawls can elegantly reply that the new "ultimate" principles render his doctrine entirely consistent with the terms of the objection.

The fourth feature of fact-insensitivity (see 3.1) is that ultimate fact-insensitive principles can be justified only by "intuition", or at any rate not by any factual considerations; either they are just believed, as with core beliefs of foundationalism, or their justification is merely that they 
promote a value that is itself accepted non-inferentially. ${ }^{27}$ But as we have seen, this is implausible in at least two ways. First, facts about human needs, goals and capacities are relevant to establishing the plausibility of any principle promoting value. These can be rendered hypothetical, we have had ample occasion to observe, but this formal device cannot conceal the justificatory relevance of these facts to the value itself. Should people be treated equally in some important way, even though they are obviously unequal in many respects? If so, some other fact about them - a capacity to frame and realise life plans that demands respect - must be more normatively determinant than other inequalities. Which is more "ultimate" here, fact or value, is as unenlightening a question as whether the location of particles determines the structure of an object or vice versa.

Moreover, as we can now state more precisely, even if value were taken as fundamental, principles must still be justified both by showing that compliance with them promotes the relevant value in forseeable circumstances, and that that value ought to be promoted rather than overridden by other values in those circumstances. On neither score are considerations of fact dispensable.

For some philosophers (Prichard, Dancy) the best candidate for a foundational ethical belief - one justified non-inferentially by "intuition" - is a particular judgement, such as "Harming this baby is wrong". On this view beliefs at the end opposite the abstract "summit" of moral reasoning are most likely not to require grounding. At the abstract summit beliefs that do not require justification are platitudes, purchasing firmness at the price of vacuity. Even low-level generalisations of particular judgements require qualification, at least for anyone who does not eschew all consequential reasoning. This is all the more so at higher levels. Certainly the sort of principles that Cohen considers non-trivial, fact-insensitive and ultimate - luck egalitarianism, act-utilitarianism, Mill's harm principle (when not itself justified by utilitarianism) - are hardly so intuitively obvious not to require defense. As I have argued, it is entirely mysterious how one could defend any (including the first mentioned, to which Cohen subscribed) without intense scrutiny of facts about humans to which the doctrine is intended to apply.

Cohen also objected to constructivism because OP parties seek regulative rules, so weigh more values than justice proper. Discovering optimal regulative rules is desirable, but precisely because the right institutional design accommodates several virtues, constructivism cannot elucidate the content of any particular virtue. "You have to understand the content of any given virtue independently of knowing what the rules of the design are in order to identify the subset of rules that reflect that particular virtue" (Cohen 2008, 286).

This issue is beyond the scope of fact-sensitivity. However, since it provides a lingering objection to converting consideration of "conditions of life" into hypothetical facts in a bulk

\footnotetext{
${ }^{27}$ While Cohen never formally defines "ultimate" principles, ultimacy presumably denotes an end to the justificatory process, implying that these principles are not justified inferentially. In any case, I am concerned with only one aspect of this: that the principles are not derived, either directly, or indirectly through the intermediary of value, from a consideration of facts.
} 
"fact-insensitive" principle endorsing the "optimal regulative rules", it may merit a brief conjectural reply. Cohen's use of "justice" as a virtue, whether of agents, institutions, or distributions, ${ }^{28}$ departs from the Aristotelian tradition whereby excessive or deficient display of a good renders it a vice. So recklessness, not courage, characterises crossing a street blindly. On the other hand, as Cohen and Feinberg affirm, one often wishes to say that justice should not be done in certain circumstances (where another value overrides).

Nevertheless, if one wants to retain the sense of justice as a generally desirable property, and if a sort of systematic departure from strict equality is generally justified, it would seem a reasonable stipulation to build that departure into the concept of justice. On this view, levelling down - e.g. in the famous reductio ad absurdum, blinding the sighted - would be more like reckless street-crossing than pursuing some worthy value albeit at the expense of another. The mad leveller (say a Pol Pot) or reckless street-crosser might be convicted, among other faults, of imprecision were they to reply to the question "What is the point?" with "I am pursuing justice (or courage) itself". Correlative virtue-neutral terms might be respectively preferable: equality (or perhaps fairness) and boldness (following Foot's suggestion) rather than justice and courage.

Rawls considered Pareto optimality, stability, and publicity to be values intricately related to justice. Cohen objects that keeping justice distinct is necessary even to identify optimal regulative rules. Here are two short replies. First, the OP parties have readily and obviously available the neutral substitute - equality, and its close relative fairness. The latter is roughly identical with Cohen's use of "justice"; Rawls treats "justice” as more complex. If OP parties have both concepts, only verbal disputation remains. Secondly, the constructive situation is intended to ensure that considerations of equality and fairness appropriately constrain the result. Both points are forcefully combined by Rawls:

Since it is not reasonable for him to expect more than an equal share in the division of social primary goods, and since it is not rational for him to agree to less, the sensible thing is to acknowledge as the first step a principle of justice requiring an equal distribution. Indeed, this principle is so obvious given the symmetry of the parties that it would occur to everyone immediately (Rawls 1977, 1999, 130).

Interestingly, another prominent objection to the DP first aired in Cohen's Tanner Lectures (1991) and expanded upon in Rescuing is that DP-sanctioned inequality reveals "an underlying tension ... between a bargaining conception and a community conception of social relationships." ${ }^{29}$ Cohen is exposing a tension in Rawls' work, but clearly favours the community conception, and would have sympathised with Crocker's (and Aristotle's) view that equality is

\footnotetext{
${ }^{28} \mathrm{He}$ discusses all three, and while giving special importance to the latter, often shifts from one to the other, even in the same passage (see below).

${ }^{29}$ Cohen 2008, 82. See generally 27-86.
} 
valuable in part to underpin communal solidarity (Crocker 1997, 6: 262-266). Community, solidarity, or fraternity is a virtue closely related to justice on this construal; distributive conceptions undermining it would thereby be unjust.

Rawls' conception is not strictly egalitarian, but prioritarian or perhaps principlepluralist (treating both equality and Pareto optimality as components of justice). ${ }^{30}$ On this construal no good purpose is served by levelling down, and the constructive procedure exemplifies this. Since envy is barred as irrational, improvements to the worst off are always favoured behind the veil, and that is too systematic a justified departure from strict equality to be considered a departure from justice. One may reject prioritarianism or pluralism, of course. But that would be a substantive disagreement, not a clarification of conceptual confusion. ${ }^{31}$

It is also beyond the scope of this paper to resolve substantive questions about the DP. Worth mentioning, however, is that the really important question raised by Cohen about the effect of the ethos of the DP versus an ethos of roughly "From each according to their ability..." is in part a question of the causal effects of adopted norms, and the potential capacities of humans to realise norms in view of the limitations of their nature. These are eminently factual not just moral considerations. The question of what the talented ought to be able to demand in return for providing services that raise the level of the worst off is a substantive question that cannot be decided independently of facts. Cohen himself sometimes exhibits this reliance. For instance, his famous argument that the "site of distributive justice" should not be confined to the basic structure, but must embrace the ethos of society, is based on the claims that

the effect of the behaviour of economic agents on people's life chances is comparably profound... the harder productive people bargain, within any stateimposed structure of rules, and the less willing they are to perform with industry and zeal under high marginal taxation, the worse off the worst off will, in general, be. (Cohen 2008, 17).

This is an actuarial calculation of its own, albeit to say what justice is not. But Cohen then repeatedly draws the positive corollary that whenever some inequality would bring about a Pareto improvement over some level of equality, a higher equality at the level of the Pareto improvement (and therefore a preferable distribution from the standpoint of justice) would be available if productive people accepted the egalitarian ethos and did not require an unequal incentive to produce the same output. Rawls agrees that "One might think that ideally individuals should want to serve one another" (Rawls 1971, 1999, 131) but considers such ideal motivation beyond the "relations of opposition in which men stand in the circumstances of justice" (Rawls

\footnotetext{
${ }^{30}$ For discussion see Casal 2007, 296-326.

${ }^{31}$ Cohen accepts and even relies on plural value to formulate his objection that constructivism fails to identify justice.
} 
1971, 1999, 131). On the other hand, if Joshua Cohen is correct, Rawls also believes that internalisation of the ethos embodied in the principles of equal liberty and opportunity will work to keep "expectations" in reasonable check when applying the DP; thus the ethos of equality does play a crucial role in preventing "excessive" inequality.

To be sure, Cohen sometimes appears to think that justice, when regarded as a property of distribution, is unaffected by the facts of human nature: what capacity humans have to live and be moved by the egalitarian ethos.

I have moved toward the view that justice is justice, whether or not it is possible to achieve it, and that to conform our conception of justice to what is achievable creates distortions in our thought and also in our practice. (Cohen 2008, 155).

Even here, however, factual considerations are unavoidable. Cohen immediately goes on to acknowledge that justice as a virtue of persons does need to consider the reason for inequality: "the nature of the causal source of the unavoidable constraint [preventing strict equality] must affect our judgment of the justice of the people in the society. If .... inequality is unavoidable for purely organizational reasons, then no stain of injustice attaches to the citizens." The "organizational reason" is of course a factual consideration in determining whether citizens are unjust. Cohen does immediately deny, contrary to my contention, that capacities are relevant: "If, however, the unavoidability is due to insurmountable cupidity, then we may say that, although they cannot be blamed for this, their very makeup is unjust: they cannot help being unjust" (Cohen 2008, 155). This assertion is important for the claim that at least justice as a property of distribution need not consider at least one important fact: human nature. But the assertion is implausible. If humans in general under the best institutions (not a few individuals with bad upbringings) could not act justly, they would be like lions and tigers who act "unjustly" toward zebras (rather than making efforts to be vegetarians). That is a peculiar extension of the concept outside its "language-game" or context in which agents have sufficient autonomy (compatibilist or incompatibilist) to exercise rational control over appetite for the sake of justice. One may speak if one wishes of the "injustice" of nature to zebras, but one need not be a Rawlsian, whether in method or substance, to find such usage inappropriate for the philosophy of justice among human agents. So radical a bifurcation between blameworthiness and injustice is surely undesirable, and a conception of justice that is in principle unrealisable is an invitation to distopia.

\section{Conclusion}

Rawls justified the DP in part with certain putative facts: that under conditions of impartiality where members of a society self-interestedly chose principles of distribution, they would accept inequalities that improved the level of the worst off, but these inequalities would 
not be significant when conjoined with the operation of other egalitarian principles they would choose. Cohen is correct to object to the derivation of the DP from these putative facts. However, he generalises the objection to the broad claim that ultimate normative principles are independent of any facts. This claim cannot be sustained, except in a very trivial sense that amounts to an empty formalism, namely, that principles that appear sensitive to actual facts $\mathrm{F}$ are sensitive only to hypothetical facts F. Moreover, Cohen himself relies on claims of actual fact to support his egalitarian rejection of the DP. Since the demands of justice are different for angels (who have no goals except serving others, and therefore for whom no beneficence is supererogatory), for humans capable of egalitarian motivation without differential incentive, and for beings too self-interested to be capable of serving the general interest, it is necessary to determine the psychological facts about the subjects of justice in question to determine what justice demands of them.

\section{References}

Aristotle. Nicomachean Ethics.

Carroll, Lewis. "What the Tortoise Said to Achilles"

Casal, Paula. "Why Sufficiency is not Enough", Ethics, 117 (2) (Jan. 2007), pp. 296-326.

Cohen, G. A. “Facts and Principles”, Philosophy and Public Affairs 31 (2003).

Cohen, G. A. Rescuing Justice and Equality (Harvard University Press: 2008).

Cohen, Joshua. “Taking People as They Are”, Philosophy and Public Affairs 2002, 30/4: 364-386.

Crocker, Lawrence, "Equality, Solidarity, and Rawls' 'Maximin'”, Philosophy and Public Affairs, 1997, 6: 262-266.

Kant, Immanuel. Groundwork to the Metaphysics of Morals (1785), (Cambridge University Press: 1998).

Kant, Immanuel. Critique of Practical Reason (1788), (Prentice Hall: 1993).

Hare, Richard. Freedom and Reason (Oxford University Press: 1977).

Kurtulmus, Faik. "Rawls and Cohen on Facts and Principles", Utilitas Vol. 21, No. 4, Dec. 2009. 
Joel Feinberg, "Rawls and Intuitionism”, ch. 5 of Norman Daniels (ed.), Reading Rawls: Critical Studies on Rawls' 'A Theory of Justice'. (Harvard University Press: 1975).

Prichard, H. A. “Does Moral Philosophy Rest on a Mistake?”, Mind, N.S., Vol. 21, 1912.

John L. Mackie. Ethics: Inventing Right and Wrong, (Viking Press: 1977).

Miller, David. "Political Philosophy for Earthlings", in Marc Stears and David Leopold (eds.), Political Theory: Methods and Approaches (OUP, 2008).

Pogge, Thomas. "Cohen to the Rescue!", in Brian Feltham (ed.), Justice, Equality and Constructivism: Essays of G.A. Cohen's Rescuing Justice and Equality (Wiley Blackwell: 2009).

Rawls, John. A Theory of Justice, $2^{\text {nd }}$ edition, (Harvard: 1971, 1999).

Ross, W. D. The Right and the Good. (Oxford: Clarendon Press, 1930).

Daniel Russell, Practical Intelligence and the Virtues (Oxford University Press, 2009).

Sen, Amartya. The Idea of Justice (Harvard UP: 2009).

Peter Singer, “All Animals are Equal”, Philosophical Exchange 1, 1974. 